\title{
Heat-exchanger piles for the de-icing of bridges
}

\author{
Fabrice Dupray $\cdot$ Chao Li $\cdot$ Lyesse Laloui
}

Received: 1 October 2013/Accepted: 3 February 2014/Published online: 16 February 2014

(C) Springer-Verlag Berlin Heidelberg 2014

\begin{abstract}
Of the various types of road structures, bridges are the most exposed to icing; the problem of icing is widely addressed through salting, which reduces the lifespan of the bridge. One promising solution to avoid the use of salt is the seasonal storage of solar heat energy captured directly through the asphalt layer; however, this solution can only be achieved cost effectively if a necessary geostructure is used as a heat exchanger. In this study, such an approach is studied for a bridge crossing a canal, and the geotechnical and energy-related challenges of such a solution are discussed. Bridge piers and abutments are located on piles, which are used as heat exchangers. Depending on local conditions, seasonal storage and natural thermal reload are two possible solutions for the operation of such a system. In particular, the presence of underground water flow is thought to be a significant factor in such a design and is considered here. This study aims to determine the geotechnical and energy design parameters through thermo-hydro-mechanical simulations. A threedimensional finite-element model analysis is necessary given the distance between bridge piles. Various underground water flow scenarios are studied. The capture of energy and de-icing requirements is based on the few existing structures that use other means of energy exchange with the ground. The results indicate that the use of heatexchanger piles for de-icing bridges can only be considered
\end{abstract}

F. Dupray · C. Li · L. Laloui $(\bowtie)$

Laboratory for Soil Mechanics (LMS), School of Architecture,

Civil and Environmental Engineering (ENAC), École

Polytechnique Fédérale de Lausanne (EPFL), GC Station 18,

1015 Lausanne, Switzerland

e-mail: lyesse.laloui@epfl.ch

L. Laloui

King Abdulaziz University, Jeddah, Saudi Arabia at specific sites; however, the efficiency of the solution at those sites is high. Possible foundation and structure stability problems are also considered, such as vertical displacements due to the dual use of the foundation piles.

Keywords Energy piles - Natural groundwater flow · THM couplings

\section{Introduction}

The formation of ice and the accumulation of snow on bridge decks and ramps have long been identified as serious problems in winter road maintenance. Because they occur earlier and more often on bridge decks and ramps than on normal stretches of road, solutions other than the typical techniques of applying road salt and snow ploughing could be employed [26]. Heating the surface of the road can only be considered as a commercially available technique in Japan, where certain bridges, steep grades, or generally dangerous areas are heated with a variety of techniques, including electrical heating, boiler, thermal water, or geothermal energy. The initial cost of a geothermal system and the operational cost of an electrical system are very high, which is why this technique is not developed in other countries. Other projects have been conducted around the world, but have remained isolated cases. Some projects were conducted in the United States, following a Department of Transportation research program [7, 19], whereas others were conducted in Europe, including Switzerland [12] and Germany [17]. The technique of heating the surface of the road was developed in the $1990 \mathrm{~s}$ but has not spread since then.

Most research on this topic has centred around the behaviour of the deck [16] and the development of usable 
software for the design of such systems [22, 24]. Most of the recent research on improving the method and reducing its cost has been performed by Miyamoto and Takeuchi [21], who found that using the bridge foundation as a heat exchanger decreased the cost considerably (up to $33 \%$ of the cost of heating the entire bridge) when compared to dedicated borehole heat exchangers (BHEs) [20]. A bridge was built using this technique in Fukui Prefecture, Japan. In this bridge, the group of piles used for an abutment foundation are also used as a heat exchanger, and solar energy recovered through the deck is used as a heat source that is seasonally stored in the foundation.

The thermal aspect of the problem has been widely studied, and design tools are available for this purpose. The thermal needs can be precisely evaluated from a statistical perspective based on local meteorological data. Uncertainties are often introduced when considering the exchange of heat with the ground, which requires local testing, such as in situ thermal response tests [18] and knowledge of local hydrogeology. Another factor that has not been considered in previous studies is the mechanical response of the foundation to the thermal solicitation. This paper focuses on the latter two points, which are treated simultaneously. A finite-element model (FEM) is used for the coupled simulation of the thermo-hydro-mechanical phenomena occurring in a heat-exchanger foundation used for bridge de-icing, including natural groundwater flow. The remainder of this paper is organised as follows. First, the existing structures will be reviewed, and the context of the bridge considered here will be discussed. Then, the model will be described, and the assumptions regarding the conditions and load path will be detailed. Finally, the results of the study will be presented and discussed.

\section{Existing structures and study context}

\subsection{Structures of interest}

Two main structures will be considered here: the Solar Energy Recovery from Road Surfaces (SERSO) project in Switzerland [12], which has a long and publicly detailed operational history, and the Shin-Kiyonaga bridge [21], which, to the authors' knowledge, is the only bridge that currently uses its own energy geostructures for de-icing purposes.

The SERSO project was the first to collect and store energy in the ground rather than simply using shallow geothermal energy. The consequences of such energy storage on the design are important, as a compact group of relatively short vertical BHEs were used instead of fewer longer BHEs that were more spread out. On the operational side, this design decision ensured that the system would display a constant performance over the long term instead of possible depletion of the heat source around the BHEs. The BHEs can be easily regrouped into one location because they do not have a structural role; thus, in the SERSO project, the BHEs define a ground volume of $46,000 \mathrm{~m}^{3}$ that is accessible for heat storage. Local conditions indicated that $100-130 \mathrm{kWh} / \mathrm{m}^{2} /$ year would be needed for de-icing, and more than $150 \mathrm{kWh} / \mathrm{m}^{2} /$ year could be retrieved from solar energy during the summer (approximately $20 \%$ of the total radiated energy). Thus, seasonal losses had to be lower than $35 \%$ to ensure continuous operation. This aspect of the design, which depends on local geology and hydrogeology, is the least studied and entails the greatest uncertainties. The system has been operational since 1994 and has tended to accumulate energy over time because the winter needs have been lower than expected. In 2009, operation of the system was halted due to pressure loss in the heat store.

The Shin-Kiyonaga Bridge is the result of the long-term effort by the Snow Management \& Construction Technology Research Center of Fukui Prefecture and the University of Fukui [20]. BHEs were the initial solution but were deemed too expensive. Thus, the group began investigating the use of energy geostructures to melt the snow and ice on roads and bridges. Initially, the foundations of nearby buildings were used with shallow geothermal energy, and a decrease in the cost was verified. Finally, a specificity of bridge foundations (tightly spaced piles) was used to turn them into an energy geostructure in combination with solar energy recovery as in the SERSO project. One large abutment, founded on 32 steel piles filled with concrete (quite a high number for such a structure), was used, representing $1,300 \mathrm{~m}$ of piles. With a spacing of $1.5 \mathrm{~m}$, these piles permit rapid access to the ground heat capacity. The cost of installing the piping in the piles was found to be $33 \%$ of the cost of equivalent BHEs, and the total cost (including deck piping and other systems) was reduced by $33 \%$.

In both cases, the thermo-mechanical consequences of using the ground (rock in the SERSO project, soil in the Shin-Kiyonaga Bridge) were not investigated. As both systems store solar energy, the temperature range that is used will be in the range of $\pm 5-10{ }^{\circ} \mathrm{C}$. A temperature difference of $20^{\circ} \mathrm{C}$ cannot be neglected mechanically because the strains and stresses that such a temperature difference can induce can reach measurable values (strains up to $3 \%$ and stresses in the MPa range).

\subsection{Study context}

The locations and characteristics of bridge foundations differ considerably from those of buildings. The mechanical response of energy piles for buildings have been 

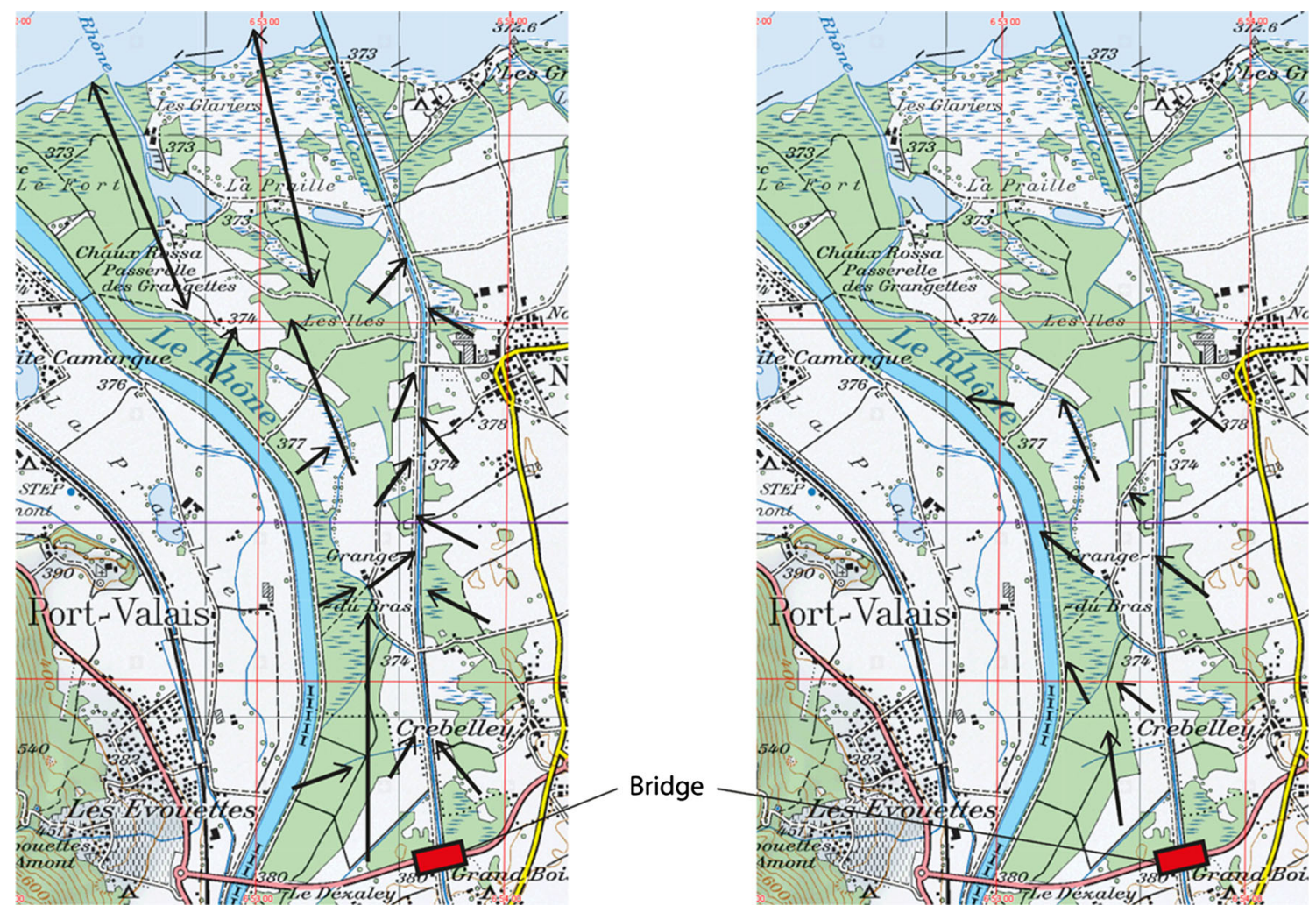

Fig. 1 Drawing of natural groundwater flow in the lower Rhône valley (Switzerland), during high water levels (left) and low water levels (right), with the selected location

studied both experimentally and numerically [1, 4, 13-15], and recent findings highlight the importance of the foundation structure in determining the behaviour of the energy piles [11]. Bridges are often used to cross waterways, which greatly increases the likelihood of having significant natural groundwater flow around the foundation. However, the number of piles is typically much lower than that for a building foundation. These two considerations are addressed here through numerical analysis using a fully coupled thermo-hydro-mechanical FEM, including natural groundwater flow. Because of the gap between the behaviour of a single pile and that of a building foundation, a complete foundation should be modelled. The model can be based on an existing bridge for which geotechnical data are available. Due to the size of the structure and based on the Japanese experience with solar heat storage, natural groundwater flow, although detrimental to heat storage, can be used positively as the thermal recharge source of a single pile. Because a bridge pier foundation typically consists of approximately 10 piles, one aim of this study was to investigate how the thermal behaviour of such a foundation compares with those of single piles or building foundations. Thus, the selected bridge should be located in a place in which there is natural groundwater flow at the depths reached by piles.
The lower Rhône valley in Switzerland can be considered favourable for the model design: as a previous swamp, it is constantly saturated just below the surface, and the natural groundwater flows are well known given the drainage system in place and the natural gravity-driven flow. The natural groundwater flows were studied by Bertrand [3], who summarised the flows as shown in Fig. 1. A bridge was recently built across the Grand Canal on the H144 road that meets all of the aforementioned conditions and is suitable for this study. Its exact location is shown in Fig. 1. The right side of the canal experiences rather constant groundwater flow that is approximately perpendicular to the bridge; the left side also experiences notable natural flow but with a changing direction.

The considered bridge is $129 \mathrm{~m}$ long over five spans and has a total deck area of $1,350 \mathrm{~m}^{2}$. Of the six foundations (piers and abutments), all but one are founded on eight piles. The length of the piles varies from 18 to $42 \mathrm{~m}$, and the diameter of the piles is $1.2 \mathrm{~m}$. Seven boreholes were drilled to investigate the characteristics of the ground, and borehole logs revealed that three main layers are encountered [9], which corresponds well to the known geology of the area. The base layer (below 10 to $20 \mathrm{~m}$ deep) is fine glaciolacustrine deposits. On top of the base layer is a 2- to-10-m-thick layer of medium-coarse glaciolacustrine 
deposits originating from the Rhône glacier retreat. The top layer is a frontal moraine layer that originated from a side glacier; the thickness of this layer varies between 3 and $9 \mathrm{~m}$.

Meteorological data are necessary for evaluating the surface of a deck that can be thermally regulated from a given length of pile. In this case, data from a nearby Meteosuisse weather station in Aigle are used to determine the energy required for de-icing and snow melting over one winter. ASHRAE (American Society of Heating, Refrigerating and Air Conditioning Engineers) guidelines [2] are applied to determine an average energy demand of $74 \mathrm{kWh} / \mathrm{m}^{2}$ based on the five coldest years among the last 20 years, with a peak of $100 \mathrm{kWh} /$ $\mathrm{m}^{2}$.

\subsection{Design modifications}

The design of the actual bridge uses piles of a large diameter $(1.2 \mathrm{~m})$ with a close spacing of $3.6 \mathrm{~m}$. This design is not suitable for energy piles due to the large amount of concrete required and the low amount of accessible volume. A variant considering the characteristics of the energy piles is derived for this study. A diameter of $1 \mathrm{~m}$ is chosen as a compromise between the tight spacing and the need for large piles due to heavy loads. Much smaller heat exchangers would be sufficient and would enable easier access to the ground heat reserve; however, such a design would require energy piles that are too long to be economically viable. The reduction in diameter must be compensated by lengthening the piles because such a foundation should be designed considering both the group as the whole and individual piles. The latter consideration (individual piles) is the main consideration here; the base surface is reduced by $36 \%$, and the friction surface is reduced by $16 \%$. Assuming a partially end-bearing pile with $33 \%$ of the load on the base, the length must be increased by $40 \%$ to obtain the same base stress and lateral friction. With an average actual length of $34 \mathrm{~m}$, the simulated pile with a smaller diameter should have a length of $48 \mathrm{~m}$. The final geometry is shown in Fig. 2.

\section{Model description}

\subsection{General THM formulation}

The diffusive model used in this simulation is implemented in the software Lagamine [8]. A brief description of these diffusive equations for a water-saturated porous medium is presented here. The equilibrium and balance equations, as well as the water and heat flows, are expressed in the moving current configuration through a Lagrangian-updated formulation [5]. The local mass conservation equation for water is as follows:

$\frac{\partial}{\partial t}\left(\rho_{w} n\right)+\operatorname{div}\left(\rho_{w} \mathbf{f}_{\mathbf{l}}\right)-Q_{w}=0$

where $\rho_{w}$ is the bulk density of water, $\mathbf{f}_{\mathbf{l}}$ is the macroscopic velocity of water, $Q_{w}$ is the volume source of water, and $n$ is the porosity.

The conservation and balance equations of the system must be expressed in terms of primary state variables $p_{w}$ and $T$. The liquid water bulk density is related to the pore water pressure $p_{w}$ and temperature $T$ through the water bulk modulus $\chi_{w}$ and volumetric water thermal expansion coefficient $\beta_{w}^{T}$ as follows:

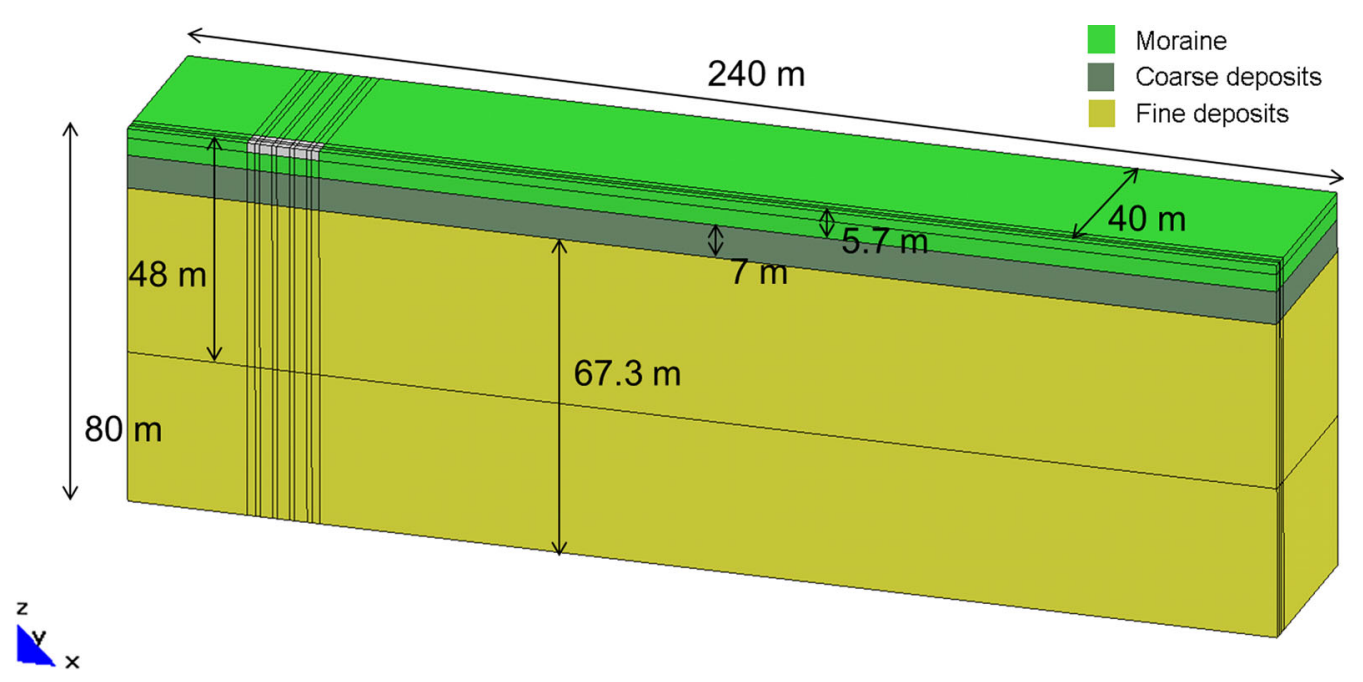

Fig. 2 Geometry of the simulated bridge pier foundation and surrounding soil with the main dimensions shown 
$\rho_{w}=\rho_{w 0}\left(1+\frac{p_{w}-p_{w 0}}{\chi_{w}}-\beta_{w}^{T}\left(T-T_{0}\right)\right)$

where $\rho_{w 0}, p_{w 0}$, and $T_{0}$ are the initial values of the water bulk density, pore water pressure, and temperature, respectively. The liquid phase motion is governed by Darcy's law:

$\mathbf{f}_{\mathbf{I}}=-\frac{k}{\mu_{w}} \operatorname{grad}\left(p_{w}\right)$

where $k$ is the isotropic intrinsic permeability and $\mu_{w}$ is the dynamic viscosity of the water, which is linearly related to temperature. Thus, the hydraulic conductivity is temperature dependent.

Collin [8] calculated the mass variation from Eq. (2) when local volume variations are added. Such a relation can be introduced in Eq. (1) and used with Eq. (3) to obtain the conventional mass conservation equation for a saturated porous medium as follows:

$n \rho_{w 0}\left(\frac{\dot{p}_{w}}{\chi_{w}}-\beta_{w}^{T} \dot{T}\right)+\rho_{w} \dot{\varepsilon}_{v}+\operatorname{div}\left(-\frac{\rho_{w} k_{w}}{\mu_{w}} \operatorname{grad}\left(p_{w}\right)\right)-Q_{w}=0$

where $\dot{X}$ is the time derivative of $X$, and $\varepsilon_{v}$ is the volumetric soil skeleton strain.

The energy balance equation of the saturated soil has the following form:

$\underbrace{\frac{\partial\left(\rho C_{p}\left(T-T_{0}\right)\right)}{\partial t}}_{\text {Heat storage }}+\underbrace{\operatorname{div}\left(\mathbf{f}_{\mathbf{T}}\right)}_{\text {Heat transfer }}-Q_{T}=0$

where $\mathbf{f}_{\mathbf{T}}$ is the heat flow, $Q_{T}$ is a volume heat source, and $\rho$ and $C_{p}$ are the density and specific heat of the mixture (solid matrix with water-filled voids), respectively. These parameters are deduced from the properties of each phase:

$\rho C_{p}=n \rho_{w} c_{p, w}+(1-n) \rho_{s} c_{p, s}$

where $\rho_{s}$ is the soil grain bulk density, and $c_{p, w}$ and $c_{p, s}$ are the specific heat of water and solid medium, respectively.

Heat transport is governed by conduction and convection:

$\mathbf{f}_{\mathbf{T}}=-\lambda \operatorname{grad}(T)+c_{p, w} \rho_{w} \mathbf{f}_{\mathbf{w}}\left(T-T_{0}\right)$

where $\lambda$ is the thermal conductivity of the mixture, as deduced from the thermal conductivity of each phase:

$\lambda=\lambda_{s}(1-n)+\lambda_{w} n$

where $\lambda_{s}$ and $\lambda_{w}$ are the thermal conductivities of the solid and liquid phases, respectively.

Finally, the mechanical balance equation is expressed as

$\operatorname{div}\left(\boldsymbol{\sigma}^{\prime}\right)+\operatorname{div}\left(p_{w} \mathbf{I}\right)+\rho \mathbf{g}=0$

where $\rho=n \rho_{w}+(1-n) \rho_{s}$ is the density of the entire medium, and $\boldsymbol{\sigma}^{\prime}$ is the material effective stress.

\subsection{Characteristics of the model}

The numerical simulations are run with FEM code Lagamine [6]. The finite-element mesh is composed of 23,760 nodes and 21,060 hexahedral isoparametric elements, and a part of the mesh is shown in Fig. 3. The fully coupled problem can be written in terms of solid displacements, water pressure, and temperature directly from Eqs. (4), (5) and (9). As can be seen, a plane of symmetry is used to reduce the size of the model. Square-section piles are used to limit the number of elements. The initial pore water pressure corresponds to the hydrostatic profile with a water table located at the surface. Temperature is imposed on all faces except the top surface, which is a no-flow boundary. The initial temperature throughout the model is $11^{\circ} \mathrm{C}$,

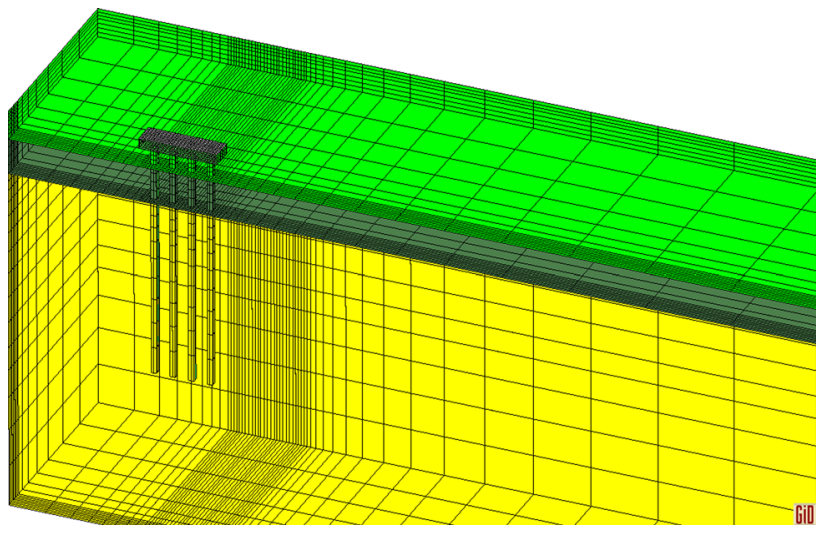

Fig. 3 Transparent view of the model mesh (see Fig. 2 for dimensions)

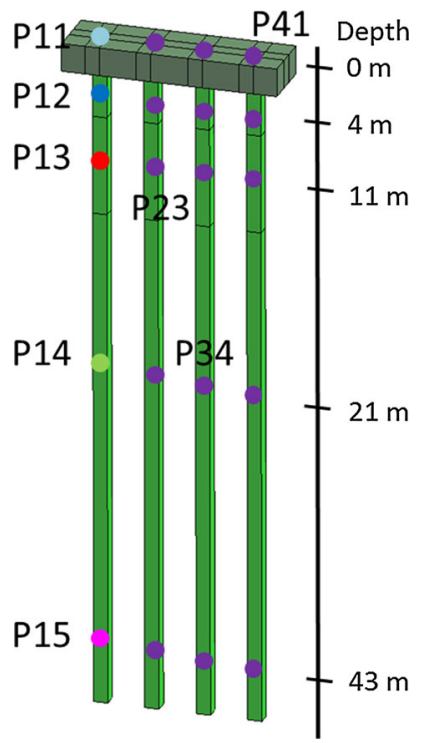

Fig. 4 View of the foundation and location of the points of interest 
which is the average value in the area. The heat exchange is represented by a heat source/sink in the volume of the pile.

The size of the model downstream is selected to prevent non-physical processes at the downstream boundary, which is at constant temperature with an imposed flow. Water reaching this boundary must be at the initial ground temperature before it reaches the area of influence of the boundary, which is achieved $200 \mathrm{~m}$ far from the foundation in this case. The analysis of the results in the pile is based on monitored locations, as described in Fig. 4, with the centre of the pile as the reference. Points at level 1 are on the surface, those at level 2 are in the moraine layer, those at level 3 are in coarse deposits, and those at levels 4 and 5 are in fine deposits.

\subsection{Boundary and initial conditions}

From a thermal perspective, the downstream boundary has a constant temperature, similar to the upstream boundary and the rear side of the model. The top surface and the plane of symmetry are adiabatic. These conditions do not consider atmospheric temperature variations because the depth of the area affected by significant variations is small compared to that of the piles. Natural temperature variations could also be induced by temperature changes in the canal, but because the canal is a drainage canal, the flow is always towards the canal, which prevents the canal temperature from influencing the ground temperature. The natural temperature of the ground in the area is $11^{\circ} \mathrm{C}$.

From a hydraulic perspective, the lateral, top, and bottom surfaces are impervious, whereas a pressure gradient of $20 \mathrm{kPa}$ is imposed between the upstream and downstream sides, corresponding to the natural slope of the area. This gradient is added to the hydrostatic pressure profile, and the resulting pressures are imposed on the sides. Mechanically, the long, short, and bottom sides are blocked in the $\mathrm{y}^{-}, \mathrm{x}-$, and z-directions, respectively; the top surface is free.

The initial mechanical loading is the body force due to gravity. The water pressure gradient is then applied until a permanent regime is reached. Finally, the part of the bridge weight corresponding to the pier $(28 \mathrm{kN})$ is applied uniformly to the foundation, defining the initial conditions for the thermal loading.

\subsection{Material parameters}

Four materials are considered in the model: concrete and three layers of soil. The mechanical, thermal, and hydraulic parameters of the model described in Sect. 3.1 are summarised in Table 1. Whereas the mechanical parameters were evaluated from the geotechnical report, the hydraulic parameters (including porosity) were evaluated from the work of Parriaux and Nicoud [25] on the hydraulic characteristics of northern alpine glacial formations.

\section{Analysis of the simulation}

As stated earlier, two scenarios are studied to determine the scenario best suited for the model and, more generally, to identify the decision factors in terms of use. The heating scenarios are represented in Fig. 5. The geothermal scenario is applied to the model with an imposed

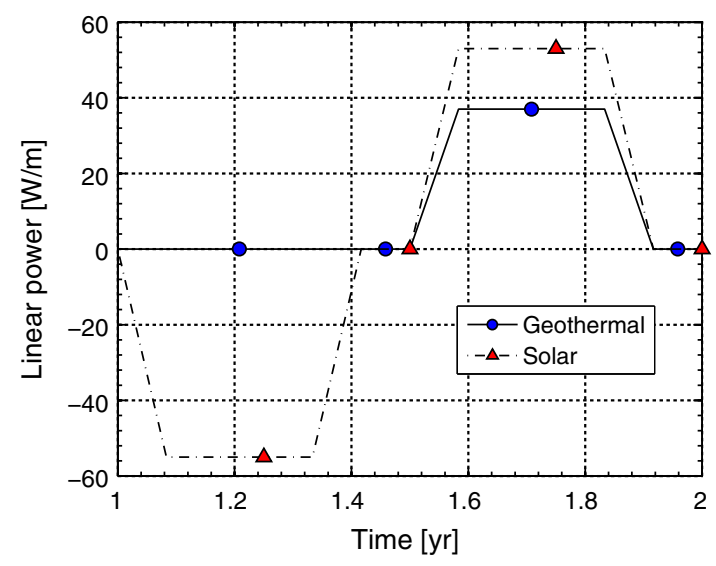

Fig. 5 Evolution of heat exchange as imposed on each pile for both scenarios. Graph starts 1st of May of the second year, and winter loading at 1.5 years starts 1 st of November

Table 1 Material parameters

\begin{tabular}{lllll}
\hline Parameter & Moraine & Coarse deposits & Fine deposits & Concrete \\
\hline Porosity $(-)$ & 0.17 & 0.34 & 0.11 & 0.12 \\
Saturated density $\left(\mathrm{kg} / \mathrm{m}^{3}\right)$ & 2,351 & 2,122 & 2,424 & 2,408 \\
Hydraulic conductivity at $20^{\circ} \mathrm{C}(\mathrm{m} / \mathrm{s})$ & $3.5 \times 10^{-6}$ & $3.5 \times 10^{-4}$ & $4 \times 10^{-5}$ & 2.02 \\
Thermal conductivity $(\mathrm{W} / \mathrm{m} / \mathrm{K})$ & 2.44 & 1.59 & 1,102 & 1.56 \\
Heat capacity $(\mathrm{J} / \mathrm{kg} / \mathrm{K})$ & 1,132 & 1,427 & $3.6 \times 10^{-5}$ & 34.045 \\
Volumetric thermal expansion coefficient $\left(\mathrm{K}^{-1}\right)$ & $3.6 \times 10^{-5}$ & $3.6 \times 10^{-5}$ & $3.6 \times 10^{-5}$ \\
Young's modulus $(\mathrm{MPa})$ & 20 & 35 & 0.3 & 35,000 \\
Poisson's ratio $(-)$ & 0.3 & & 0.2 \\
\hline
\end{tabular}


natural groundwater flow, whereas the solar scenario is used without natural groundwater flow. Winter use is the same in both cases, with a ramp-up period of 1 month, a constant-use period of 3 months, and a ramp-down period of 1 month. Solar recharge occurs in the summer along the same pattern for the solar case. Different levels of imposed constant power are considered in both cases so that the minimum temperature reached in a pile is $0{ }^{\circ} \mathrm{C}$.

\subsection{Natural groundwater flow and geothermal recharge}

The pressure gradient imposed corresponds to a flow of $0.25 \mathrm{~m} / \mathrm{d}$ in the layer of coarse deposits but only $0.03 \mathrm{~m} / \mathrm{d}$ in the main layer and even less in the top layer. Thus, strong temperature heterogeneities are expected to occur in the piles. A design power of $37 \mathrm{~W} / \mathrm{m}$ can be used without freezing the pile. This value is lower than those obtained for a single energy pile used in comparable natural groundwater flows (both 0.015 and $0.3 \mathrm{~m} / \mathrm{d}$ were tested, giving values of 42 and $70 \mathrm{~W} / \mathrm{m}$, respectively) in [10], showing a decreased efficiency. Figure 6 presents a contour plot of temperature at the end of the second extraction period (time 1.92 years). Figures 7 and 8 present the temperature evolution in one pile and at one depth in all four piles, respectively. The thermal interaction between the piles is the most evident reason for the decrease in efficiency; as shown in Fig. 6, the temperature field around the piles in fine deposits is homogeneous, with no separation between each pile's area of influence. In addition, in the coarse layer, only the first two piles reach a steady state during the extraction period, whereas temperature in the last two piles decreases continuously, as an isolated pile

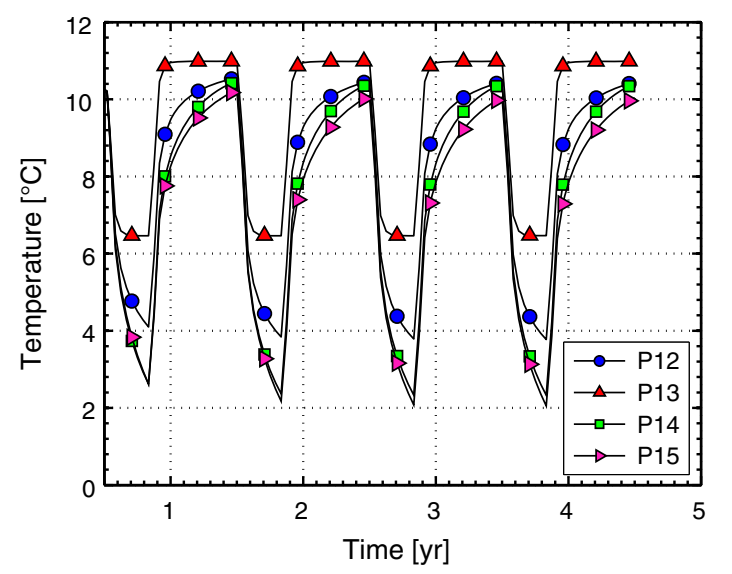

Fig. 7 Temperature evolution in pile 1 for four locations along the pile

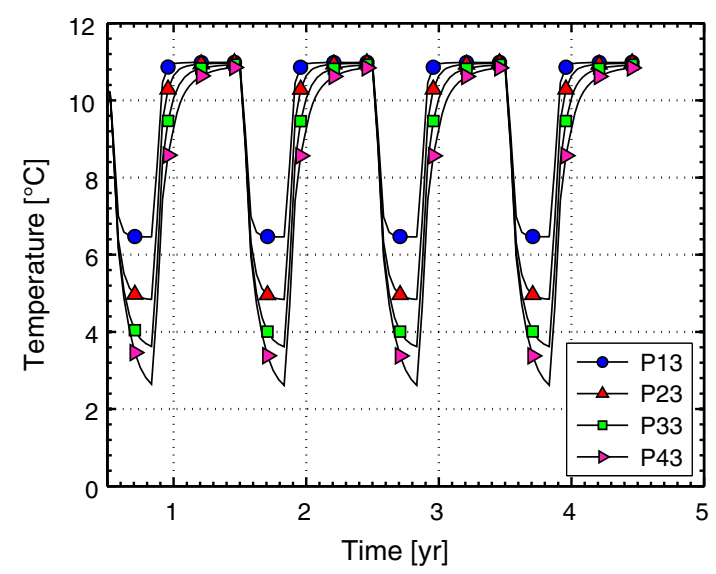

Fig. 8 Temperature evolution in the four piles in the middle of the coarse layer

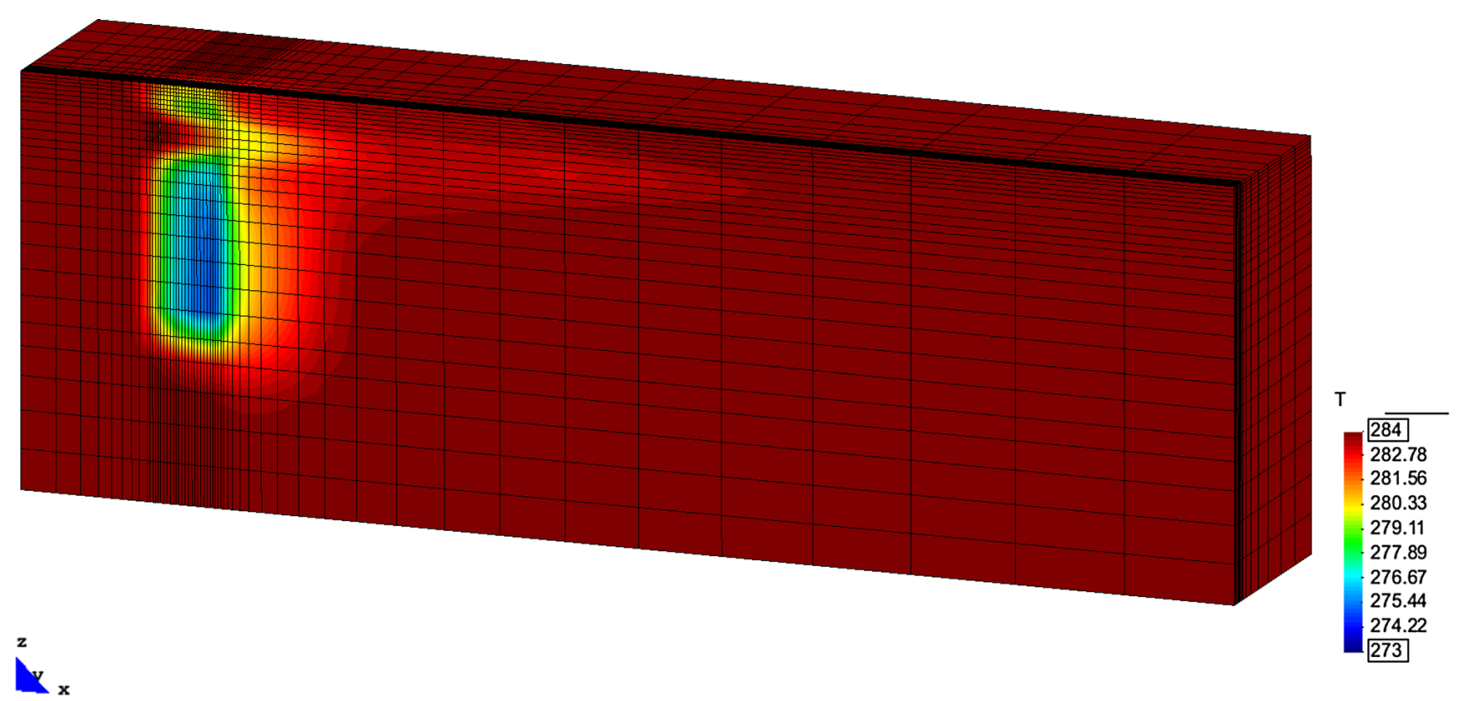

Fig. 6 General view of the temperature field at the end of the second extraction period, with remnants of the first extraction period cold bulb visible at the end of the plume 

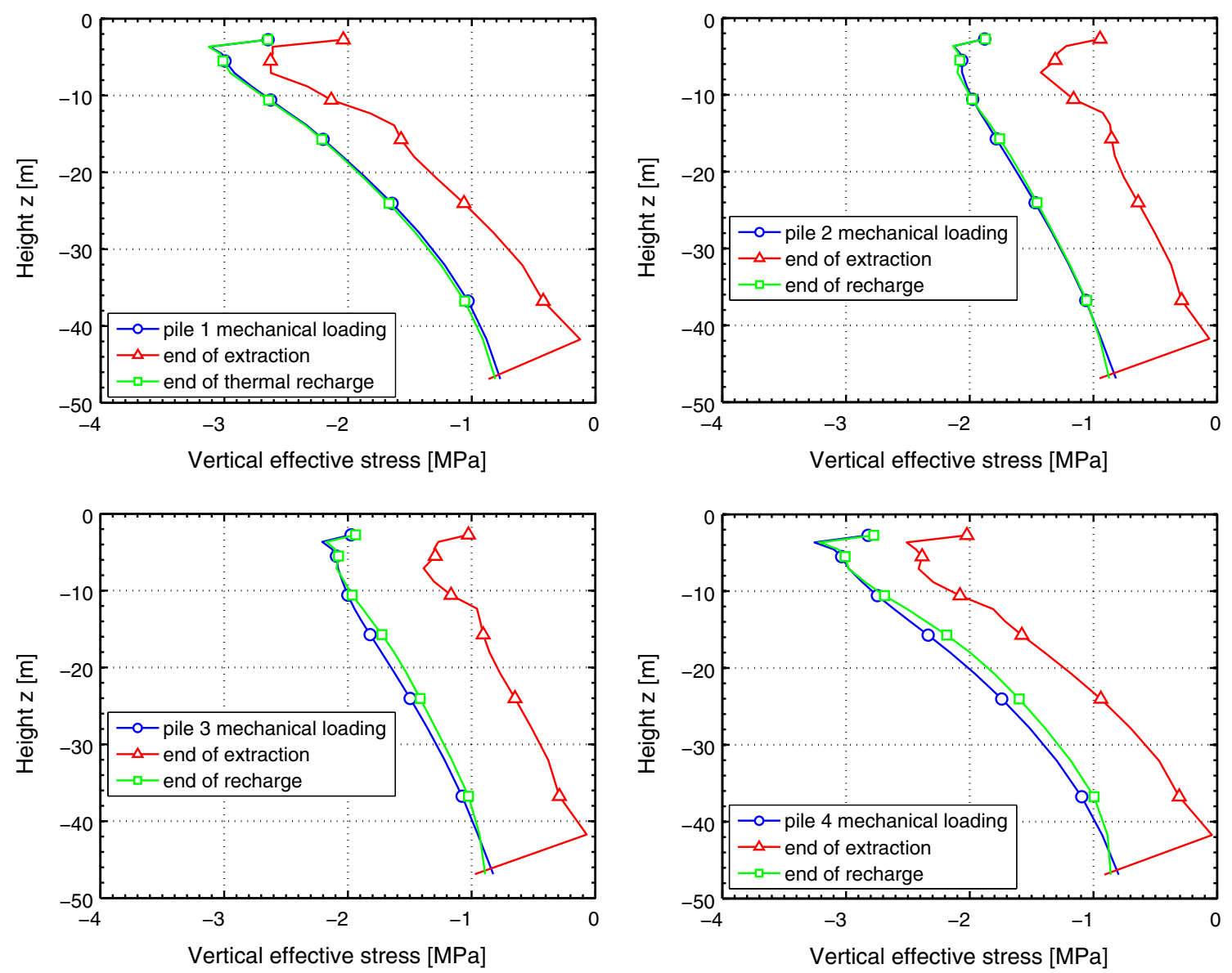

Fig. 9 Vertical effective stress profiles in all four piles, for the mechanical loading alone, after heat extraction and after natural recharge
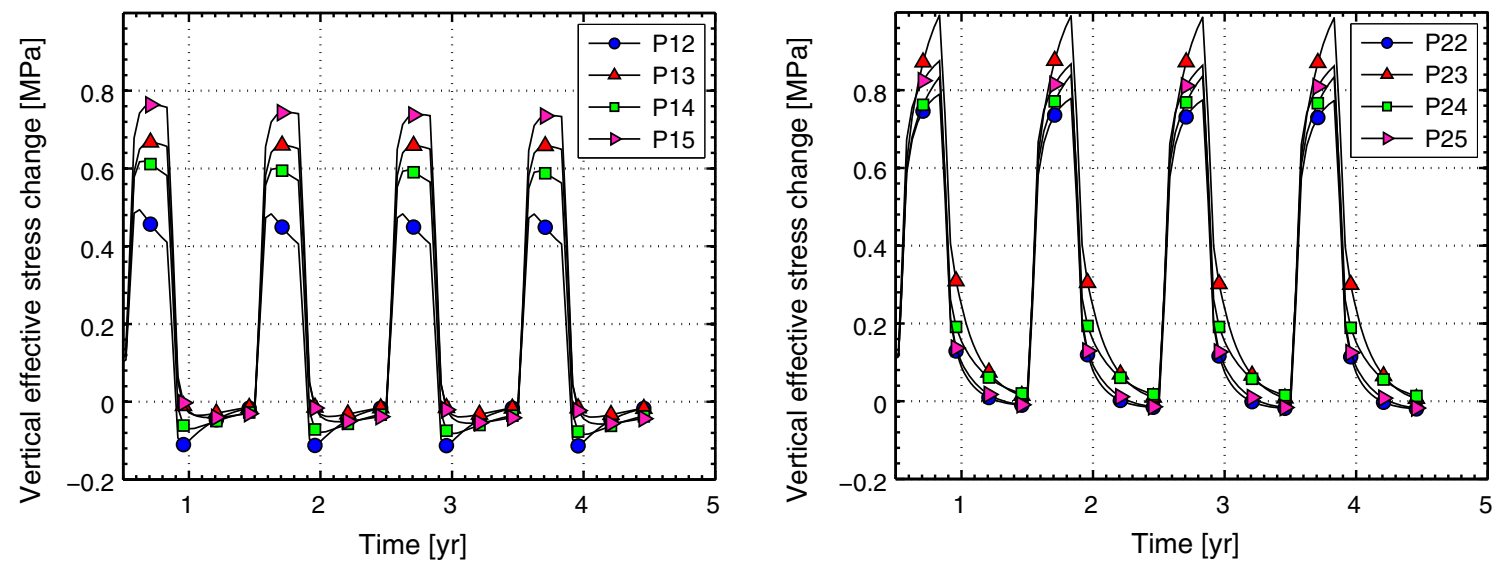

Fig. 10 Evolution of thermally induced vertical effective stress at four locations in piles 1 and 2

would in an area with a lower natural groundwater flow. However, the thermal recharge of the pile in this area is still complete before the next extraction period (see Fig. 8). Thermal recharge is better in the upper part than in the bottom part but is not complete (no return to $11^{\circ} \mathrm{C}$, as shown in Fig. 7). The neighbouring coarse layer in which convection occurs facilitates thermal recharge in the top part, whereas the bottom part can only be returned to the natural temperature by conduction, with a slight effect linked to the natural groundwater flow. This aspect is the limiting part of the energy pile in terms of extracted energy. The design power observed here means that each 
meter of energy pile is able to provide the energy needs of $1.4 \mathrm{~m}^{2}$ of deck.

The second consideration is the mechanical response of the foundation to thermal loading. Figure 9 presents vertical stress profiles of the piles to highlight the differences between them. Central piles are less loaded than the lateral piles due to the strong group effect. However, the magnitude of the thermally induced stresses in the central piles is slightly larger, as confirmed by Fig. 10. Figure 9 also illustrates the fact that the natural recharge does not bring all piles back to the natural temperature, as the stress state at the end of the recharge for piles 3 and 4 is not identical to the initial stress state. The decrease in stress is not uniform along the pile, as it is minimal in the moraine layer, increases considerably in the coarse layer, and decreases in the top of the fine deposit layer before increasing to its maximum towards the bottom of the pile. This trend results from a combination of non-uniform temperature and non-uniform soil properties. The magnitude of the effect reaches $72 \mathrm{kPa} /{ }^{\circ} \mathrm{C}$, which is approximately five times more than that acting on an isolated pile. The value is consistent, given the small size of the foundation, with the few measured values in building foundation reported by Amatya et al. [1], from 100 to $200 \mathrm{kPa}$. The main risk of this effect is that the bottom of the pile may enter a tensile state, thus necessitating reinforcement bars along the entire pile. An interesting aspect found by comparing Fig. 10 with Fig. 7 is that in pile 1, the decrease in stress is not directly correlated with the increase in temperature. In contrast, the two trends are correlated for pile 2, highlighting the higher restraint that the central piles undergo compared to the outer piles in such a compact group of piles (Fig. 11).

Another aspect of the mechanical response is the induced displacements at the surface level. The foundation is found to settle slightly (up to $3.5 \mathrm{~mm}$ ) during winter, which is acceptable for any road bridge. The slight tilt observed due to the natural groundwater flow is also of interest. The magnitude of this tilt is also acceptable compared to the size of the foundation.

\subsection{No groundwater flow and solar recharge}

As shown in Fig. 5, a design power of $53 \mathrm{~W} / \mathrm{m}$ can be used in this case. For a system using solar recharge, this rather low value [11] is caused by the overly large thermal interaction between the piles. The other main reason for this low value can be observed in Fig. 12. Even during the month when heat is injected at a lower rate, thermal losses are higher than the amount of heat injection, meaning that the temperature in the area decreases. The average temperature in the area drops from 23 to $18{ }^{\circ} \mathrm{C}$ in 2 months, representing an energy loss of $40 \%$. Although this energy loss can be considered high, a $35 \%$ loss was considered acceptable in the SERSO project [23]. The main difference with an isolated pile is that the design power with solar

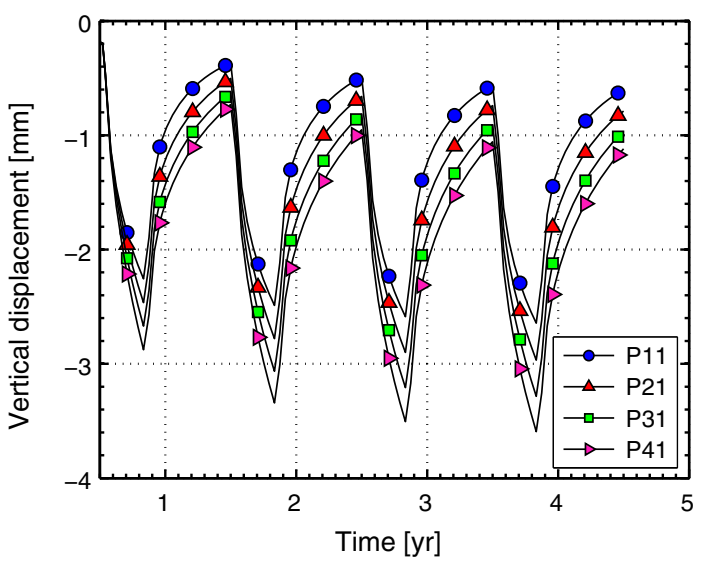

Fig. 11 Evolution of the foundation displacements

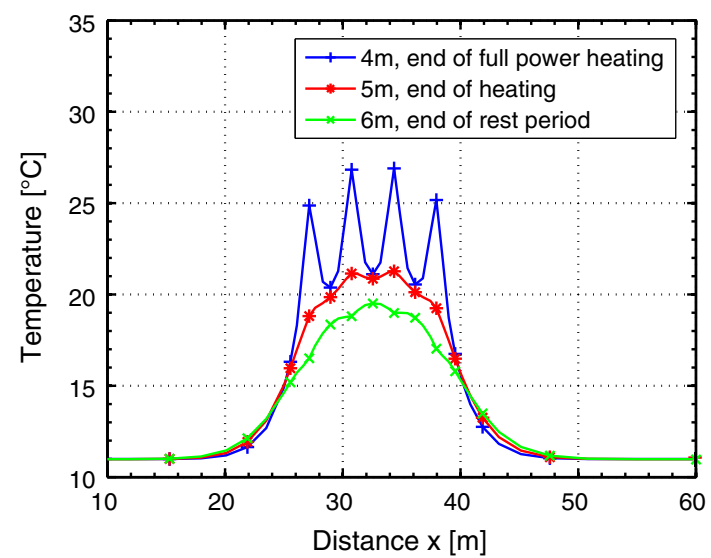

Fig. 12 Temperature profile along the $x$-axis at a depth of $21 \mathrm{~m}$, illustrating heat losses at the end of recharge

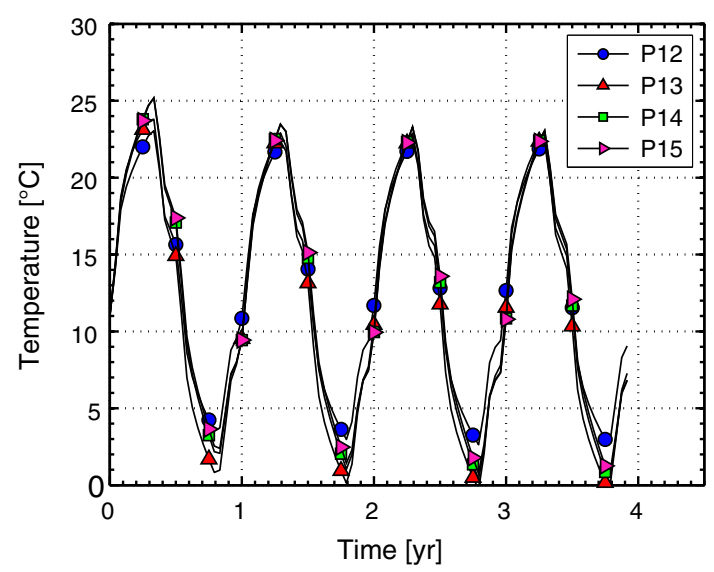

Fig. 13 Temperature evolution in pile 1 at four different depths 

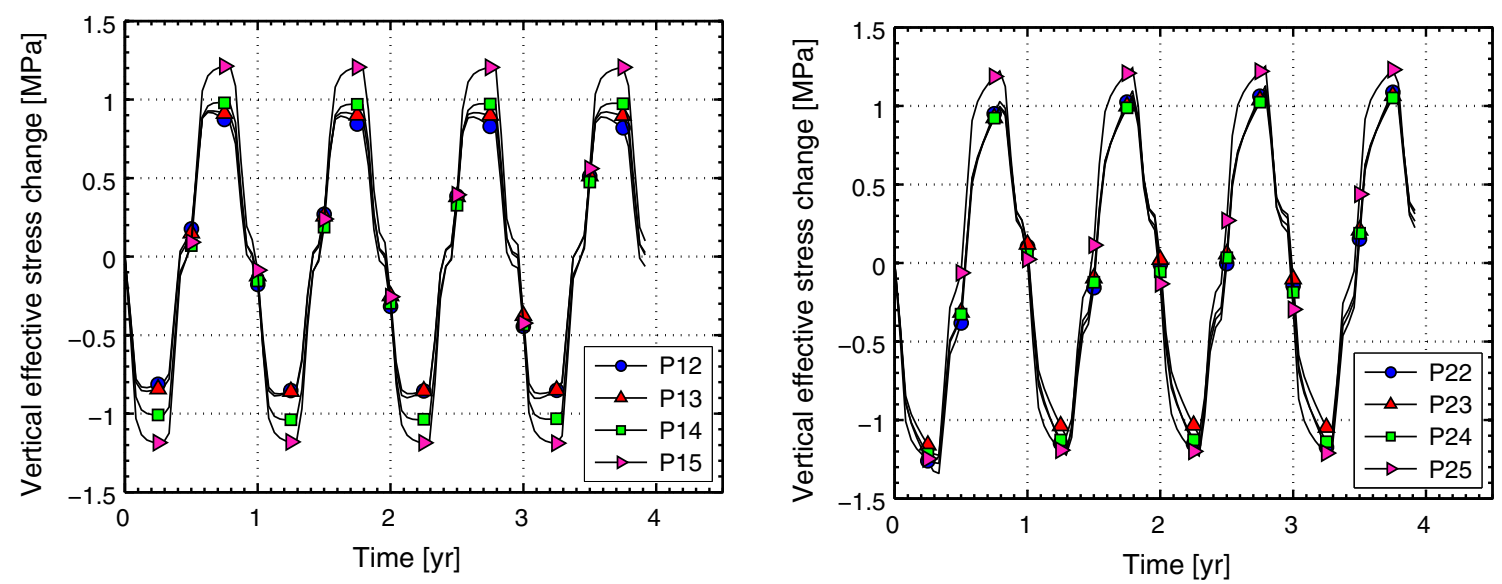

Fig. 14 Evolution of thermally induced vertical stress at four locations in piles 1 and 2

recharge is now higher than that achieved with natural groundwater flow. Figure 13 presents the evolution of temperature in one pile. The temperature is found to be very homogeneous, with the minimal temperature reached in the low-conductivity layer (coarse deposits), as expected. In this case, the ratio of pile length to deck surface for the energy piles needed to provide the required amount of energy for de-icing reaches $2 \mathrm{~m}^{2} / \mathrm{m}$.

The main mechanical aspect of the problem is illustrated in Fig. 14, which presents the evolution of thermally induced stresses for piles 1 and 2. The thermally induced stresses are clearly directly linked with not pile temperature but short-term local temperature difference. Most of the increase (decrease) in stress occurs at the onset of injection (extraction), when the area experiences maximal temperature gradients. This phenomenon highlights the strong interactions between the piles, both from thermal (temperature gradients disappear faster than for widely spaced energy piles) and mechanical perspectives (the piles move as a group with the ground). The overstress reaches $80 \mathrm{kPa} /$ ${ }^{\circ} \mathrm{C}$ during injection and $90 \mathrm{kPa} /{ }^{\circ} \mathrm{C}$ during extraction (on average), which is slightly higher than with natural recharge. The displacements are homogeneous and almost proportional to the temperature in the piles, with values between +4.2 and $-2.2 \mathrm{~mm}$, which is not significant.

\section{Conclusions}

In this study, an alternative design of a bridge foundation is studied to include energy piles for the de-icing of the bridge deck. The case study is chosen to include most representative characteristics of a bridge foundation, including type, size, nature of the soil, and hydrogeology. After energy needs are evaluated, a fully coupled simulation of the problem is conducted with a finite-element code.
This simulation represents the evolution of an eight-pile foundation and the surrounding ground submitted to imposed heat exchange through the piles. One novel aspect of this model is the inclusion of natural groundwater flow in the thermo-hydro-mechanical problem. The importance of the natural groundwater flow in the thermal behaviour of the foundation is demonstrated, with strong temperature variations between the layers. A mechanical response is observed that differs notably from that of an isolated pile or a building foundation; this behaviour occurs because the foundation acts as a group of piles. The thermally induced stress is higher when expressed as a function of temperature, and it is connected to not only pile temperature but also the temperature gradient within the area. The observed displacements are compatible with those deemed acceptable on a long structure, such as a bridge. Importantly, the efficiency of the system is in line with actual ratios of total bridge surface to total pile length, which can reach $2 \mathrm{~m}^{2} / \mathrm{m}$ in the best-case scenario. This ratio can be used to identify projects for which using energy piles for bridge de-icing may be a cost-effective solution, as the construction of additional piles would be unnecessary.

Acknowledgments This study was funded by the Swiss Federal Office for Roads and the Association of Road Professionals (VSS) through Project VSS 2010/503. The authors also thank the University of Liège, whose Lagamine software was used in the simulations.

\section{References}

1. Amatya B, Soga K, Bourne-Webb PJ, Amis T, Laloui L (2012) Thermo-mechanical behaviour of energy piles. Géotechnique 62(6):503-519

2. ASHRAE (1995) Snow melting. In: ASHRAE (ed) Heating, ventilating and air-conditioning Applications, vol 4. ASHRAE Handbook. Atlanta, pp 46.41-13

3. Bertrand J (1986) Palier 10-Les Evouettes, étude hydrogéologique: rapport sur l'état de la nappe d'eau souterraine après 
trois années d'étude (1983-1985). Evaluation des impacts d'un barrage sur la nappe et recommendations, Hydro-Rhône SA pour EOS (in French)

4. Bourne-Webb PJ, Amatya B, Soga K, Amis T, Davidson C, Payne P (2009) Energy pile test at Lambeth College, London: geotechnical and thermodynamic aspects of pile response to heat cycles. Géotechnique 59(3):237-248

5. Charlier R (1987) Approche unifiée de quelques problèmes non linéaires de mécanique des milieux continus par la méthode des éléments finis. $\mathrm{PhD}$ thesis, Université de Liège, Belgium (in French)

6. Charlier R, Radu J-P, Collin F (2001) Numerical modelling of coupled transient phenomena. Rev Fr Génie Civ 5(6):719-743

7. Chiasson A, Spitler J (2001) Modeling approach to design of a ground-source heat pump bridge deck heating system. Transp Res Rec J Transp Res Board 1741(1):207-215

8. Collin F (2003) Couplages thermo-hydro-mécaniques dans les sols et les roches tendres partiellement saturés. $\mathrm{PhD}$ thesis, Université de Liège, Belgium (in French)

9. Conus \& Bignens, Amsler Bombeli \& Associés (2009) Rapport géotechnique pour le Pont sur le Grand Canal, H144 (in French)

10. Dupray F, Mimouni T, Laloui L (2013) Alternative uses of heatexchanger geostructures. In: Laloui L, Di Donna A (eds) Energy geostructures. Wiley, Hoboken, pp 119-138

11. Dupray F, Laloui L, Kazangba A (2014) Numerical analysis of seasonal heat storage in an energy pile foundation. Comput Geotech 55:67-77

12. Eugster WJ, Schatzmann J (2002) Harnessing solar energy for winter road clearing on heavily loaded expressways. Paper presented at the XIth PIARC Winter Road Congress, Sapporo, Japan, 28-31 Jan 2002

13. Knellwolf C, Péron H, Laloui L (2011) Geotechnical analysis of heat exchanger piles. J Geotech Geoenviron Eng (ASCE) 137(10):890-902

14. Laloui L, Di Donna A (eds) (2013) Energy Geostructures: Innovation in underground engineering. Civil engineering and geomechanics series. ISTE Ltd. and John Wiley and Sons, Hoboken

15. Laloui L, Nuth M, Vulliet L (2006) Experimental and numerical investigations of the behaviour of a heat exchanger pile. Int $\mathrm{J}$ Numer Anal Meth Geomech 30(8):763-781
16. Liu X, Rees SJ, Spitler JD (2007) Modeling snow melting on heated pavement surfaces. Part I: Model development. Appl Therm Eng 27(5-6):1115-1124

17. Mackert K-U (2011) Kanalbrücke Berkenthin mit temperierter Fahrbahn (A bridge with thermally-controlled roadway in Berkenthin). Paper presented at the Expertengespräch Stahlbrückenbau, Bergisch Gladbach, DE, 27 Sept 2011 (in German)

18. Mattsson N, Steinmann G, Laloui L (2008) Advanced compact device for the in situ determination of geothermal characteristics of soils. Energy Build 40(7):1344-1352

19. Minsk LD (1999) Heated bridge technology: Report on ISTEA Sec. 6005 Program FHWA-RD-99-158, Federal Highway Administration, Washington, DC, USA

20. Miyamoto S, Takeuchi M (2002) Snow-melting and de-icing system on road using natural thermal energy sources. Paper presented at the XIth PIARC Winter Road Congress, Sapporo, Japan, 28-31 Jan 2002

21. Miyamoto S, Takeuchi M (2005) Snow-melting system on road using seasonal energy storage through foundation piles for bridge. In: Proceedings of JSCE (Japan Society of Civil Engineers) 797:51-62 (in Japanese)

22. Nagai N, Miyamoto S, Nishiwaki M, Takeuchi M (2009) Numerical simulation of snow melting on pavement surface with heat dissipation pipe embedded. Heat Transf Asian Res 38(5):313-329

23. Pahud D (2007) Serso, stockage saisonnier solaire pour le dégivrage d'un pont. Rapport final, Office fédéral de l'énergie, Berne $(\mathrm{CH})$

24. Pahud D (2008) BRIDGESIM: outil de simulation pour le dégivrage de pont par énergie solaire (BRIDGESIM: a simulation tool for bridge de-icing with solar energy). Paper presented at the 15. Schweizerisches Status-Seminar "Energie- un Umweltforschung im Bauwesen", Zürich, CH (in French)

25. Parriaux A, Nicoud G (1993) De la montagne à la mer, les formations glaciaires et l'eau souterraine. Exemple du contexte Nord-alpin occidental. Quaternaire 4(2-3):61-67 (in French)

26. Perrier N, Langevin A, Campbell JF (2006) A survey of models and algorithms for winter road maintenance. Part I: system design for spreading and plowing. Comput Oper Res 33(1):209-238 